\title{
ACE polymorphism is a determinant for COVID-19 mortality in the post-vaccination era
}

https://doi.org/10.1515/cclm-2021-1001

Received September 11, 2021; accepted September 13, 2021;

published online October 14, 2021

Keywords: angiotensin-converting enzyme polymorphism; COVID-19; mortality.

To the Editor,

The COVID-19 pandemic has been responsible for over 4,500,000 lethal cases worldwide by September 2021. Despite a huge vaccination campaign by all European countries in 2021, COVID-19 still causes a considerable human toll. As COVID-19 prevalence and mortality partially depends on genetic factors [1, 2], we have studied the potential effect of several genetic polymorphisms on COVID-19 mortality in the post-vaccination period. Incidence and case mortality data from 26 European countries were compared with the proportion of fully vaccinated people in each country, and the phenotype distribution of several genetic polymorphisms: ABO blood group, galactoside 2-alpha-L-fucosyltransferase 2 (FUT2), deletion/insertion (D/I) of angiotensin-converting enzyme 1 (ACE1), complement C3, haptoglobin, vitamin D binding protein (DBP), the cystic fibrosis mutation, and the homeostatic iron regulator protein (HFE). Data from Austria, Belgium, Bulgaria, Croatia, Cyprus, Czechia, Denmark, Estonia, Finland, France, Germany, Greece, Hungary, Italy, Luxemburg, Malta, the Netherlands, Norway, Poland, Portugal, Romania, Slovakia, Slovenia, Spain, Sweden, and the UK, as communicated by the European Centre for Disease Prevention and Control were included in the study [3].

*Corresponding author: Joris R. Delanghe, Department of Clinical Chemistry, Ghent University, C. Heymanslaan 10, 9000 Ghent, Belgium, E-mail: joris.delanghe@ugent.be. https://orcid.org/00000002-5702-6792

Marijn M. Speeckaert and Marc L. De Buyzere, Department of Internal Medicine, Ghent University, Ghent, Belgium
Table 1 summarizes the final model of a multiple regression model (after stepwise elimination of the nonsignificant genetic polymorphisms). In this model, the relative mortality (the ratio of death rate and case rate in a given country) was compared to the vaccine uptake in adults, week 34, 2021 for each country. As expected, vaccination protects against COVID-19 mortality ( $\mathrm{p}=0.0026$ ). Furthermore, also the ACE1 D/I polymorphism independently contributes $(\mathrm{p}=0.0076)$ to COVID-19 mortality (see Figure 1).

The ACE1 gene is characterized by a genetic $\mathrm{D} / \mathrm{I}$ of an Alu repeat in intron 16 and this polymorphism (rs1799752) shows an important geographical variation [4]. The ACE1 DD genotype is associated with lower expression of ACE2 in human tissues [4]. As SARS-CoV-2 host cell attachment is predominantly facilitated by the ACE2 receptor [5], ACE2 counteracts the effects of its homolog ACE1 [6]. An ACE1/ACE2 imbalance plays an important role in SARS-CoV-2 infectivity and COVID-19 progression [6]. Whereas the ACE1 D allele seems to be protective in the unvaccinated population [1, 2], on the other hand, the ACE1 D allele has been associated with an increased risk of hypertension, pre-eclampsia, heart failure, cerebral infarct, diabetic nephropathy, encephalopathy, asthma, severe hypoglycaemia in diabetes, gastric cancer, and poor prognosis following kidney transplant. Many of these

Table 1: Multivariate model for predicting relative COVID-19 mortality for 26 European countries (death rate/case rate) $\left(r^{2}=0.535, p=0.0002\right)$. Data from September 3, 2021.

\begin{tabular}{|c|c|c|c|}
\hline Parameter & Coefficient & $\begin{array}{r}\text { Standard } \\
\text { error }\end{array}$ & t p-Value \\
\hline Constant & -0.1211 & & \\
\hline $\begin{array}{l}\text { Vaccination coverage } \\
\text { (\% fully vaccinated } \\
\text { adults) }\end{array}$ & -0.001614 & $0.000478-3.385$ & 50.00261 .024 \\
\hline $\begin{array}{l}\text { ACE1 D allele } \\
\text { frequency }\end{array}$ & 0.00495 & $0.00169 \quad 3.309$ & 90.00761 .024 \\
\hline
\end{tabular}

ACE, angiotensin-converting enzyme 1 ; VIF, variance inflation factor. 


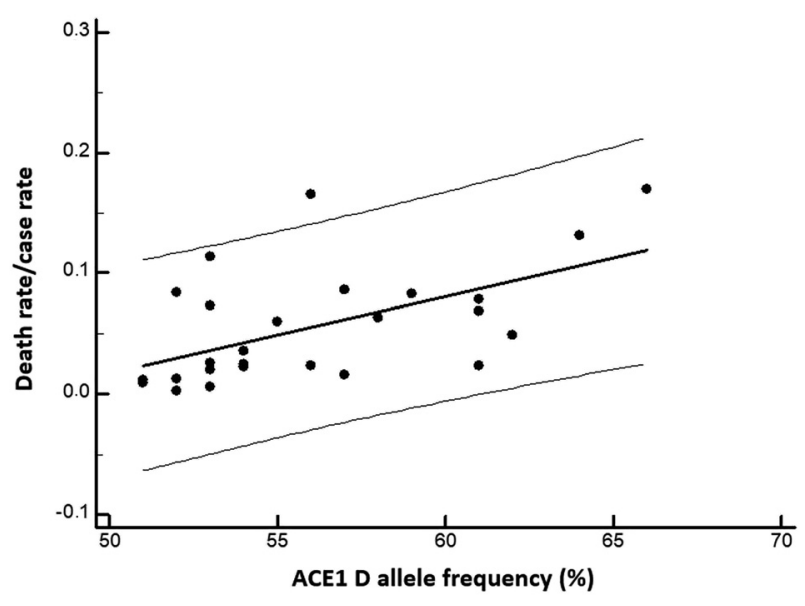

Figure 1: Relative mortality due to COVID-19 and ACE1 D allele frequency in 26 European countries.

$\mathrm{Y}$ (relative mortality due to COVID-19) $=0.00636 \mathrm{X}$ (ACE1 D allele

frequency, \%) $-0.300\left(r^{2}=0.3122 ; p=0.01\right)$.

conditions have been associated with a poorer outcome following COVID-19 infection [8]. On the positive side, the ACE1 D allele confers greater upper-body strength in old age. The ACE1 I allele, meanwhile, offers improved endurance/athletic performance and aerobic capacity, although it does increase the risk of obstructive sleep apnea in hypertensives [7].

Next to the expected effect of the widespread vaccination campaign, in Europeans the ACE1 D allele appears to be a major confounding factor in COVID-19 mortality, which is able to partially explain the pronounced geographical differences in COVID-19 in the post-vaccination era.

Research funding: None declared.
Author contributions: All authors have accepted responsibility for the entire content of this manuscript and approved its submission.

Competing interests: Authors state no conflict of interest. Informed consent: Not applicable.

Ethical approval: The local Institutional Review Board deemed the study exempt from review.

\section{References}

1. Delanghe JR, Speeckaert MM, De Buyzere ML ML. COVID-19 infections are also affected by human ACE1 D/I polymorphism. Clin Chem Lab Med 2020;58:1125-6.

2. Delanghe JR, De Buyzere ML, Speeckaert MM. Genetic polymorphisms in the host and COVID-19 infection. Adv Exp Med Biol 2021;1318:109-18.

3. Available from: https://www.ecdc.europa.eu/en/covid-19/ situation-updates [Accessed 3 Sep 2021].

4. Jacobs M, Lahousse L, Van Eeckhoutte HP, Wijnant SRA, Delanghe JR, Brusselle GG, et al. Effect of ACE1 polymorphism rs1799752 on protein levels of ACE2, the SARS-CoV-2 entry receptor, in alveolar lung epithelium. ERJ Open Res 2021;7:00940-02020.

5. Letko M, Marzi A, Munster V. Functional assessment of cell entry and receptor usage for SARS-CoV-2 and other lineage $B$ betacoronaviruses. Nat Microbiol 2020;5:562-9.

6. Gemmati D, Bramanti B, Serino ML, Secchiero P, Zauli G, Tisato V. COVID-19 and individual genetic susceptibility/receptivity: role of ACE1/ACE2 Genes, immunity, inflammation and coagulation. Might the double $X$-chromosome in females be protective against SARS-CoV-2 compared to the single $X$-chromosome in males? Int J Mol Sci 2020;21:3474.

7. Gard PR. Implications of the angiotensin converting enzyme gene insertion/deletion polymorphism in health and disease: a snapshot review. Int J Mol Epidemiol Genet 2010;1:145-57.

8. Dessie ZG, Zewotir T. Mortality-related risk factors of COVID-19: a systematic review and meta-analysis of 42 studies and 423,117 patients. BMC Infect Dis 2021;21:855. 